KREATIF

Jurnal Ilmiah

Prodi Manaiemen Universitas Pamulang
Pamulang ISSN : $2339-0689$, E-ISSN : 2406-8616

J. KREATIF, Vol. 7, No. 2, Desember 2019 (Halaman 52-58)

Tersedia Online di : http://openjournal.unpam.ac.id/index.php/kreatif

\title{
PENGARUH TERPAAN IKLAN SHOPEE DI TELEVISI DAN CITRA MEREK TERHADAP PERILAKU KONSUMTIF REMAJA KOTA TENGERANG SELATAN
}

\author{
Farahdilla Emia', M.Ravii Marwan², \\ Jurusan Ilmu Komunikasi Fakultas Ilmu Komunikasi \\ Dosen Universitas Gunadarma Margonda Depok \\ farahdillae@gmail.com ${ }^{1}$,ravii@ staffsite.gunadarma.ac.id ${ }^{2}$
}

\begin{abstract}
ABSTRAK
Tujuan penelitian ini adalah mengetahui pengaruh terpaan iklan shopee di televisi dan citra merek terhadap perilaku konsumtif remaja kota tangerang selatan.

Metode Penelitian ini survei kuantitatif dengan paradigma positivme. Subjek penelitian ini adalah remaja kota tengerang selatan yang berumur 18 hingga 22 tahun, dengan jumlah sampel 400 orang responden berdasarkan teknik Purposive Sampling. Teori yang digunakan pada penelitian ini adalah Teori Terpaan Media (Media Exposure) Dan menggunakan Teori SOR asumsi dasar teori ini adalah media massa menimbulkan efek yang terarah dan reaksi khusus langsung kepada kemunikan.

Hasil dari penelitian ini merumuskan Ha diterima, artinya terdapat pengaruh yang signifikan antara terpaan iklan shopee di televisi dan citra merek terhadap perilaku konsumtif di kalangan remaja Kota Tangerang Selatan, dengan kata lain terpaan iklan dapat memengaruhi pembelian implusif, pemborosan, dan pembelian tidak rasional yang merupakan faktor dari perilaku konsumtif. Sedangkan uji F, terpaan iklan secara parsial hanya variabel intensitas menonton saja yang berpengaruh positif dan signitifikan. kedua variabel secara simultan berpengaruh terhadap perilaku konsumtif mahasiswa, Korelasi Determinasi menunjukkan tingkat pengaruh yang cukup erat pada terpaan iklan 66,2\% terhadap perilaku konsumtif sedangkan sisanya sebanya $33,8 \%$ dipengaruhi oleh variabel lain.
\end{abstract}

Kata kunci : citra merek, perilaku konsumtif, terpaan iklan

\section{ABSTRACT}

This study aims to determine the effect of exposure to shopee advertisements on television and brand image on the consumptive behavior of adolescents in South Tangerang.

This research method is quantitative survey with positivme paradigm. The subject of this research is the southern city of South Tangerang, aged 18 to 22 years, with a total sample of 400 respondents based on purposive sampling technique. The theory used in this study is the Media Exposure Theory (Media Exposure) and using the SOR Theory the basic assumption of this theory is the mass media cause a directed effect and a special reaction directly to the uniqueness.

The results of this study formulate Ha accepted, which means that there is a significant influence between exposure to shopee ads on television and brand image on consumer behavior among adolescents of South Tangerang City, in other words advertising exposure can affect implusive purchases, wasteful, and irrational purchases which are factors of consumptive 
behavior. While the F test, ad exposure partially only the intensity of the watching variable had a positive and significant effect. the two variables simultaneously influence the student's consumptive behavior, Determination Correlation shows a fairly close level of influence on the exposure of advertising $66.2 \%$ to consumptive behavior while the remaining $33.8 \%$ is influenced by other variables.

Keywords: brand image, consumptive behavior, ad exposure

\section{PENDAHULUAN}

Pada zaman pemasaran yang sangat modern ini, banyak bermunculan para wiruahusawan baru secara tidak langsung akan bermunculan pula persaingan-pesaing dikalangan wirausahawan. Hal ini mewajibkan setiap wirausahawan harus memiliki strategi yang unik dan bagus agar mempertahkan produk atau jasa yang akan di jual. suatu produk atau jasa agar mampu menguasi pasar. Adapun salah satu strategi yang dapat dijalankan untuk memempertahkan itu salah satunya yaitu meningkatkan aktivitas promosi. Promosi merupakan hal yang sangat dibutuhkan oleh perusahaan untuk memasarkan produk atau jasa yang dijual. Bisa juga dijadikan sebagai salah satu acuan dalam menentukan keberhasilan program pemasaran. Promosi memiliki tujuan untuk memberikan informasi, membujuk, dan mengingatkan calon pembeli pada sebuah perusahaan dan produk yang dihasilkannya. Salain itu Promosi juga mampu membantu seluruh pihak yang terlibat dalam proses pemasaran yaitu untuk memperbaiki dan memperlanjut hubungan antara produsen dengan konsumen. Dengan demikian perlu diketahui bahwa setinggi apapun kualitas dari suatu produk, jika calon pembeli belum mengenal, mendengar, bahkan tidak yakin akan manfaat yang diberikan suatu produk atau jasa maka mereka tidak akan pernah tertarik untuk membeli atau memakai jasa tersebut.

Salah satu bagian dari bauran promosi adalah iklan. mengatakan bahwa iklan ialah bentuk dari komunikasi tidak langsung, yang disadari oleh masyarakat tentang keunggulan suatu prosuk, yang di kemas sedemikian rupa untuk menimbulkan rasa ketertarikan yang kemudian akan mengubah pikiran seseorang untuk melakukan pembelian. Periklanan juga dianggap sebagai salah satu media yang paling sering digunakan oleh perusahaan untuk mengarahkan komunikasi persuasif kepada konsumen. Agar proses penyampaian iklan dapat diterima dengan baik oleh target maka hal yang perlu diperhatikan yaitu dalam memilih media periklanan yang tepat. Media untuk mempromosikan iklan terdiri dalam beberapa bagian seperti media cetak, elektronik, spanduk, baliho dan lain sebagainya.

Walaupun iklan tidak secara langsung berdampak pada pembelian atau penggunaaan produk atau jasa. Suatu iklan dianggap sebagai pemasaran yang efektif dalam mepererat komunikasi yang baik antara wirausahawan dan konsumen.

Menampilkan sebuah iklan yang kreatif akan menimbulkan daya tarik bagi setiap orang yang meilihat iklan tersebut. Iklan yang kreatif mampu membuat penonton memperhatikan iklan tersebut hingga detail dan rinci. Oleh sebab itu, sebuah perusahaan harus berusaha memberikan berbagai keunikan dan berbagai kretivitas iklan agar promosi yang dilakukan di media berjalan dengan lancar dan dapat memuaskan konsumen. Dalam hal 
ini portal penjualan secara online mempunyai berbagai inovasi yang akan menimbulkan dampak- dampak yang bernilai negatif ataupun positif pada kehidupan mahasiswa diantar lain adalah perubahan perilaku dalam kehidupan bermasyarakat dan perilaku konsumtif. dampak positif dari perilaku tersebut antara lain mahasiswa dapat berwirausaha dengan membuka usaha sesuai dengan potensi dan peluang untuk mendapatkan keuntungan atau mendapatkan penghasilan sendiri. Lalu dampak negatif antara lain perkembangan teknologi menyebabkan menjamurnya penjualan secara online, berdampak pada masyarakat menjadi konsumtif dengan membeli barang-barang yang tidak sesuai dengan kebuthannya. Hal ini disebabkan oleh gaya hidup masyarakat.

Gaya hidup dalam masyarakat memberikan kecendrungan kepada masyarakat tertentu untuk membeli barang-barang atau menggunakan jasa sesuai dengan gaya hidup mereka. Perilaku konsumtif dan gaya hidup berkaitan erat. Untuk memenuhi tuntutan dalam gaya hidup masyarakat menjadi konsumtif dengan membeli barang-barang yang tidak produktif dan kadang kala tidak sesuai dengan kemampuan. Dengan Perkembangan teknologi misalnya melalui internet menyebabkan perilaku konsumtif meningkat.

\section{KERANGKA TEORI}

Penelitian ini menggunakan metode kuantitatif, dengan Teori Terpaan Media (Media Exposure). Teori ini mengemukakan bahwa penggunaan media oleh masyarakat dapat diklasifikasikan. Adanya kebutuhan dasar sosial dan psikologis yang didasari oleh media massa atau sumber-sumber lainnya yang mempengaruhi pola terpaan media yang menghasilkan kebutuhan, dan konsekuensi.

Media exposure atau terpaan media adalah sautu penggunaan media oleh masyarakat yang meliputi jumlah waktu, jenis isi media, intensitas, dan hubungan antar khalayak dan media yang digunakan. Werner J. Severin dan James Q. Tankard, Jr (2005). "Penelitian ini juga menggunakan teori stimulus respons (S-O-R). Sekitar tahun 1930-an, muncul suatu model komunikasi klasik yang sebagian besar dipengaruhi oleh teori psikologi. Psikologi dan ilmu komunikasi memiliki objek material yang sama yaitu manusia yang jiwanya memiliki komponen sikap, opini, perilaku, kognisi, afeksi dan konasi. Menurut stimulus response ini, efek yang ditimbulkan adalah reaksi khusus terhadap stimulus khusus, sehingga seseorang dapat mengharapkan dan memperkirakan kesesuaian antara pesan dan reaksi komunikan (Effendy 2003).

\section{METODE PENELITIAN}

Penelitian ini dilakukan dengan menyebarkan kuesioner. Berdasarkan hasil perhitungan dari rumus lemeshow didapatkan responden sebanyak 400 orang dengan tingkat kepercayaan 95\%. Teknik yang digunakan pada penelitian ini adalah Teknik Purposive Sampling yaitu salah satu teknik non random sampling dimana peneliti menentukan pengambilan sampel dengan cara menetapkan ciri-ciri khusus yang sesuai dengan tujuan penelitian sehingga diharapkan dapat menjawab permasalahan penelitian. Purposive Sampling dengan kriteria yang ditentukan oleh peneliti diantaranya responden yang berdomisili di wilayah Kota Tanggerang Selatan dan 
remaja akhir 18 sampai dengan 22 tahun.

Penelitian ini menggunakan kkuesioner sebagai instrumen penelitian dengan total pertanyaan 36 butir. Instrumen penelitian yang berisi kkuesioner dengan pertanyaan indikator masing-masing yang digunakan sebelumnya telah diuji validitas dan realibilitas menggunakan bantuan program SPSS. Analisis data yang digunakan dalam penelitian ini adalah analisis kuantitatif.

Untuk menguji hipotesis dalam penelitian ini digunakan uji statistika menggunakan analisis uji T. Uji hipotesis pada dasarnya menunjukkan seberapa jauh pengaruh satu variabel independen secara individual dalam menerangkan variabel dependen (Imam Ghozali, 2006)

Pengujian ini dilakukan dengan menguji signifikan hubungan variabel independen dan variabel dependen yaitu apakah masing-masing dari variable Terpaan Iklan $\left(\mathrm{X}_{1}\right)$, citra merek $\left(\mathrm{X}_{2}\right)$ ) benar-benar berpengaruh terhadap variabel perilaku konsumtif $(\mathrm{Y})$. apabila $\mathrm{t}$ hitung $>\mathrm{t}$ tabel dan tingkat signifikansi < alpha $(0,05)$, maka variabel independen secara individual atau parsial berpengaruh terhadap variabel dependen. (Imam Ghozali, 2006).

\section{HASIL PENELITIAN}

Temuan penelitian terkait masing- masing indikator pada masingmasing variabel dalam penelitian ini adalah pada variable $\mathrm{X}_{1}$ yaitu variabel terpaan iklan Shopee di televisi didapatkan hasil sebesar 0,220 menunjukkan bahwa setiap peningkatan 1 satuan pada variabel ini akan meningkatkan pengaruh perilaku konsumtif terhadap remaja sebesar 0,220. Sehingga artinya responden memahami dengan baik pesan yang didapatkan melalui iklan dan mendapatkan terpaan yang tinggi.

Selanjutnya pada variabel X2 yaitu Citra merek didapatkan hasil sebesar 0,229 menunjukkan bahwa setiap peningkatan 1 satuan pada variabel ini akan meningkatkan pengaruh perilaku konsumtif terhadap remaja sebesar 0,229 .

Pada variabel Y atau Konstanta (a) sebesar 32,092 artinya jika variabel $\mathrm{X}$ sama dengan nol, maka perilaku konsumtif nilainya adalah 32,092, selain itu nilai konstanta tersebut juga menyatakan bahwa perilaku konsumtif positif. Yaitu perilaku konsumtif (Y) yang dipengaruhi oleh Terpaan Iklan $\left(\mathrm{X}_{1}\right)$ dan Citra Merek $\left(\mathrm{X}_{2}\right)$ menunjukkan hasil sebesar 32,092.

Hasil uji hipotesis yaitu analisis regresi linier berganda menggunakan uji simultan (uji F) dan uji parsial (uji T). Berikut ini adalah hasil uji F yaitu digunakan dalam pengujian hipotesis secara bersama-sama. Uji F dilakukan untuk menguji hubungan signifikansi antara variabel bebas dan variabel terikat secara keseluruhan.

Hasil perhitungan ststistik menunjukkan bahwa nilai $\mathrm{F}$ hitung $(4,878)>$ F tabel $(2,627)$ dan nilai signifikansinya sebesar $0,000<0,05$. Hal ini menunjukkan bahwa Ha diterima dan Ho ditolak, yakni secara simultan terpaan iklan dan Citra Merek berpengaruh dan signifikan terhadap perilaku konsumtif.

Hasil uji hipotesis dengan uji $\mathrm{T}$ bertujuan untuk mengetahui apakah variabel bebas secara individual mempunyai pengaruh terhadap variabel terikat dalam penelitian sebagai berikut

Berdasarkan perhitungan statistik diketahui bahwa nilai pengaruh 
terpaan iklan $\left(\mathrm{X}_{1}\right)$ dengan $\mathrm{t}$ hitung sebesar 5,289 > 19,995. Selain itu nilai signifikansinya $0,000<0,05$. Maka $\mathrm{H} 1$ diterima dan Ho ditolak. Sehingga dapat disimpulkan bahwa Terpaan iklan $\left(\mathrm{X}_{1}\right)$ berpengaruh positif dan signifikan terhadap perilaku konsumtif (Y).

Berdasarkan perhitungan statistik diketahui bahwa nilai pengaruh citra merek (X2) dengan $\mathrm{t}$ hitung sebesar 1,993 > 19,965. Selain itu nilai signifikansinya $0,000<0,05$. Maka $\mathrm{H}_{2}$ diterima dan Ho ditolak. Sehingga dapat disimpulkan bahwa citra merek $\left(\mathrm{X}_{2}\right)$ berpengaruh positif dan signifikan terhadap perilaku konsumtif (Y).

hasil dari uji t parisal, setelah selesai mendapatkan hasil melalui SPSS versi 22 maka selanjutnya adalah pengujian hipotesis yang telah peneliti buat. Adapun hipotesis penelitian ini adalah sebagai berikut :

$\mathrm{H} 1$ : terdapat pengaruh terpaan iklan shopee di televisi terhadap prilaku konsumtif remaja

$\mathrm{H}_{2}$ : terdapat pengaruh Citra merek shopee di televisi terhadap prilaku konsumtif remaja

Ho : Tidak terdapat pengaruh terpaan iklan dan citra merek terhadap perilaku konsumtif remaja.

\section{PEMBAHASAN}

Dari hasi uji regresi linier berganda, didapatkan nilai $\mathbf{Y}=\mathbf{3 2 , 0 9 2 +}$ 0,220X1 + 0,229X2 . Dari hasil tersebut, dapat dikatakan bahwa apabila nilai $\mathrm{X}$ itu 0 (tidak ada), maka konstanta $\mathrm{Y}$ sama dengan 32,092. Itu berarti, variabel $\mathrm{Y}$ atau perilaku konsumtif remaja kota tangerang selatan memiliki nilai. Dalam artian remaja kota tangerang selatan sudah terkena terpaan iklan yang menumbulkan perubahan perilaku menjadi konsumtif.

Dalam penelitian ini diperoleh nilai determinasi $(\mathrm{R})$ variabel $\mathrm{X} 1$ sebesar 0,580 atau $58,0 \%$ dan variabel $X_{2}$ sebesar 0,704 atau $56,8 \%$. Nilai ini menjelaskan bahwa perilaku konsumtif para remaja kota tangerang selatan dipengaruhi oleh terpaan iklan dan citra merek. Sedangkan sisanya yaitu 50,3\% merupakan pengaruh dari faktor-faktor lain diluar penelitian ini.

Berdasarkan pengujian hipotesis dapat diketahui nilai Sig atau angka signifikasi penilitan Variabel X1 adalah 0,220 artinya setiap kenaikan variabel terpaan iklan shopee (X1) sebesar 1 satuan pada variabel ini akan meningkatkan pengaruh perilaku konsumtif remaja (Y) sebesar 0,220. Selain itu nilai signifikansinya $0,000<0,05$. Maka H1 diterima dan Ho ditolak. Sehingga dapat disimpulkan bahwa Terpaan iklan (X1) berpengaruh positif dan signifikan terhadap perilaku konsumtif (Y).

Lalu perhitungan oleh nilai koefisien regresi X2 sebesar 0,220 menunjukkan bahwa setiap peningkatan 1 satuan pada variabel ini akan meningkatkan pengaruh perilaku konsumtif remaja (Y) sebesar 0,220. Selain itu nilai signifikansinya $0,000<0,05$. Maka $\mathrm{H} 2$ diterima dan Ho ditolak. Sehingga dapat disimpulkan bahwa citra merek (X2) berpengaruh positif dan signifikan terhadap perilaku konsumtif (Y)

\section{KESIMPULAN}

Penelitian ini adalah penelitian kuantitatif yang mengkaji seberapa besar hubungan pengaruh secara parsial dan simultan antara variabel bebas 
yaitu Terpaan Iklan televisi e-commerce shopee versi ramadhan big sale dan Citra Merek terhadap variabel terikat yaitu perilaku konsumtif dikalangan remaja kota tangerang selatan. Setelah dilakukan pengolahan data degan metode statistik beserta analisisnya dengan menggunakan bantuan hitungan statistika, maka dapat diambil kesimpulan sebagai berikut :

1. Ditemukan bahwa terpaan iklan televisi shopee versi ramadhan big sale secara parsial berpengaruh langsung terhadap peningkatan perilaku konsumsi remaja kota tangerang selatan. Hal ini ditunjukkan oleh nilai koefisien regresi X1 sebesar 0,220 artinya setiap kenaikan variabel terpaan iklan shopee (X1) sebesar 1 satuan pada variabel ini akan meningkatkan pengaruh perilaku konsumtif remaja (Y) sebesar 0,220. Selain itu nilai signifikansinya $0,000<0,05$. Maka H1 diterima dan Ho ditolak. Sehingga dapat disimpulkan bahwa Terpaan iklan (X1) berpengaruh positif dan signifikan terhadap perilaku konsumtif (Y). Hasil lainnya adalah bahwa citra merek shopee versi ramadhan big sale secara parsial berpengaruh secara langsung peningkatan perilaku konsumsi remaja kota tangerang selatan. Hal ini di tunjukan oleh nilai koefisien regresi X2 sebesar 0,220 menunjukkan bahwa setiap peningkatan 1 satuan pada variabel ini akan meningkatkan pengaruh perilaku konsumtif remaja (Y) sebesar 0,220. Selain itu nilai signifikansinya $0,000<0,05$. Maka $\mathrm{H} 2$ diterima dan Ho ditolak. Sehingga dapat disimpulkan bahwa citra merek (X2) berpengaruh positif dan signifikan terhadap perilaku konsumtif (Y).

2. Selain itu dalam perhitungan lebih lanjut diketahui bahwa terpaan iklan shopee di televisi versi ramadhan big sale dan citra merek secara simultan atau bersama - sama berpengaruh terhadap perilaku konsumtif, dengan Hasil perhitungan statistik pada Uji F menunjukkan bahwa nilai $\mathrm{F}$ hitung $(4,878)>\mathrm{F}$ tabel $(2,627)$ dan nilai signifikansinya sebesar $0,000<0,05$. Hal ini menunjukkan bahwa Ha diterima dan Ho ditolak, yakni secara simultan terpaan iklan, Citra Merek berpengaruh dan signifikan terhadap perilaku konsumtif.

3. Pada model S-O-R (Stimulus Organism Respons) relevan dalam penelitian ini. Dimana teori ini mempunyai efek merupakan reaksi terhadap stimulus setelah terkenanya terpaan media iklan shopee di televisi lalu, konsumen mencari tahu tetang citra pada perussahaan shopee tersebut, jika citra tersebut positif maka konsumen akan menimbulkan respon untuk melakukan pembelian terus menerus hanya karena ingin mengikuti mode, mencoba produk baru, bahkan hanya untuk memperoleh pengakuan sosial dengan dominasi faktor emosi sehingga menimbulkan perilaku konsumti

\section{SARAN}

Berdasarkan kesimpulan dan keterbatasan penelitian yang dilakukan, sehingga saran-saran yang dapat penulis berikan:

1. Bagi PT. Shopee Internasional Indonesia

Diharapkan dalam hal ini PT. Shopee Internasional Indonesia dapat meningkatkan citra pada e-commerce shopee ini, iklan yang sudah ada saat ini telah mendapatkan apresiasi yang baik dari masyarakat. Untuk itu perlu penambahan ide - ide yang lebih kreatif, inovatif dan berbeda dari yang lain agar bisa mempertahankan yang sudah dibangun sampai 
saat ini dan berusaha untuk terus meningkatkan kualitas aplikasi dan iklan shopee agar mampu membuat khalayak tertarik. Penelitian ini juga diharapkan untuk dapat menjadi bahan masukan dan pertimbangan untuk mengetahui bagaimana respon khalayak terhadap iklan ecommerce shopee yang ditayangkan oleh media televisi.

2. Bagi Peneliti Selanjutnya

Hasil korelasi dari kedua variabel independen menyatakan erat. Menunjukkan kemampuan variabel bebas mempengaruhi variabel terikatnya $58 \%$ dan $70,4 \%$. pengaruh dari variabel X1 masih sangat kecil, oleh karena itu bagi peneliti yang akan meneliti dengan tema yang sama, sebaiknya menambah jumlah variabel bebas (independen), agar hasil penelitian dapat lebih baik lagi dalam membuktikan hipotesis. Seperti Brand Equity, Brand Awareness, dll

\section{DAFTAR PUSTAKA}

A.M, Morissan. 2008. Manajemen Media Penyiaran: Strategi Mengelola Radio dan Televisi. Jakarta: Kencana Prenada Media Group 2010. Periklanan Komunikasi Pemasaran Terpadu. Jakarta : kencana Prenada Media Group

Ardianto, Elvinaro. 2007. Komunikasi Massa Suatu Pengantar. Bandung : Simbosa Rekatama Media Aker. 1997. Menejemen Ekuitas Merek. Jakarta : Spektrum Mitra Utama

Eriyanto. 2013. Analisis Naratif Dasar- Dasar dan Penerapan dalam Analisis Teks Berita Media. Jakarta: Kencana

Ferrinadewi, Erna. 2008. Merek dan Psikologi Konsumen. Yogyakarta : Graha Ilmu

Ghozali, Imam. 2006. Aplikasi Analisis Multivariate dengan Program SPSS edisi ke 4. Semarang : Badan Penerbit Universitas Diponegoro

Gunarsa, Singgih D. 2004. Psikologi Perkembangan Anak dan Remaja. Jakarta : Gunung Mulia

Hackley, Chris. 2005. Advertising dan Promosi. London : Sage

Hoeffler, Stave and Keller, Kevin Lane. 2010. The Marketing Advantage of Strong Brands. New Jersey : Prentice Hall

Kaller and Kevin Lane. 2003. Strategic Brand Management : Building, Measuring, and Managing Brand Equaity. New Jersey : Prentice Hall

Kotler and Keller. 2013. Komunikasi Pemasaran Terpadu. Bandung : CV Pustaka Setia Littlejohn, Stephen W \& Karen A. 2009.

Nurdin. 2014. Pengantar Komunikasi Massa. Jakarta : Rajawali Pers 2007. Pengantar Komunikasi Massa. Jakarta : PT Rajagrafindo Persada 